\title{
Clinical Outcomes of EGFR Exon 20 Insertion Mutations in Advanced Non-small Cell Lung Cancer in Korea
}

Seonggyu Byeon, MD'
Youjin Kim, MD'
Sung Won Lim, MD'1
Jang Ho Cho, MD'1
Sehoon Park, MD'1
Jiyun Lee, MD'1
Jong-Mu Sun, MD, PhD'
Yoon-La Choi, MD, PhD²
Se-Hoon Lee, MD, PhD'
Jin Seok Ahn, MD, PhD'
Keunchil Park, MD, PhD'
Myung-Ju Ahn, MD, PhD'1

${ }^{1}$ Division of Hematology-Oncology, Department of Medicine, ${ }^{2}$ Department of Pathology, Samsung Medical Center, Sungkyunkwan University School of Medicine, Seoul, Korea

Correspondence: Myung-Ju Ahn, MD, PhD Division of Hematology-Oncology, Department of Medicine, Samsung Medical Center, Sungkyunkwan University School of Medicine, 81 Irwon-ro, Gangnam-gu, Seoul 06351, Korea Tel: 82-2-3410-3452

Fax: 82-2-3410-1754

E-mail: silk.ahn@samsung.com

Received March 12, 2018

Accepted July 19, 2018

Published Online July 23, 2018

\begin{abstract}
Purpose
Epidermal growth factor receptor (EGFR) exon 20 insertion mutations account for approximately $4 \%$ of all EGFR mutations. Given the rarity of this mutation, its clinical outcomes are not fully established.
\end{abstract}

\section{Materials and Methods}

Between 2009 and 2017, non-small cell lung cancer (NSCLC) patients who showed an exon 20 insertion were retrospectively reviewed for clinical characteristics and outcomes, including responses to chemotherapy (CTx) or targeted therapy.

\section{Results}

Of 3,539 NSCLC patients who harbored an activating EGFR mutation, 56 (1.6\%) had an exon 20 insertion. Of the advanced NSCLC patients, 27 of 1,479 (1.8\%) had an exon 20 insertion. The median overall survival was 29.4 months (95\% confidence interval 9.3 to 49.6) for 27 advanced NSCLC patients. The 22 patients who received systemic CTx achieved a $50.0 \%$ response rate and a $77.2 \%$ disease control rate, with 4.2 months of progressionfree survival. Six patients received EGFR tyrosine kinase inhibitors (TKIs). Three of the four patients that had only an exon 20 insertion showed progressive disease, while one showed stable disease. The other two patients had an exon 20 insertion and another EGFR mutation and achieved a partial response.

\section{Conclusion}

The incidence of an exon 20 insertion mutation is rare in Korea and occasionally accompanied by other common EGFR mutations. Although the response to systemic CTx. in these patients is comparable to that of patients with other mutations, the response rate to firstor second-generation EGFR TKIs is quite low. Therefore, the development of a more efficient agent is urgently needed.

\section{Introduction}

Lung cancer is a leading cause of cancer death worldwide [1,2]. In Korea, 24,000 cases are newly diagnosed, and 17,440 patients die of lung cancer each year [2]. Approximately $80-85 \%$ of lung cancers are classified as non-small cell lung cancer (NSCLC) [3]. The discovery of relevant genomic abnormalities in NSCLC has led to the development of novel,

\author{
Key words \\ Non-small cell lung cancer, Exon 20 insertion, \\ Epidermal growth factor receptor, Mutation, \\ EGFR tyrosine kinase inhibitor
}


include an in-frame deletion in exon 19 and the L858R mutation in exon 21. Together, these account for $90 \%$ of EGFR mutations [6].

EGFR tyrosine kinase inhibitors (TKIs) are associated with a highly effective and durable response in NSCLC patients with these common EGFR mutations, often yielding 9-13 months of progression-free survival (PFS) and more than 24 months of overall survival (OS) [7-9]. Other, less commonly observed EGFR mutations (such as G719X or L861Q) account for $2 \%-3 \%$ of EGFR mutations and are also considered responsive to EGFR TKIs [10].

EGFR exon 20 insertion mutations are typically located just after the C-helix of the tyrosine kinase domain of EGFR, and their incidence varies between $1 \%$ to $9 \%$ of all EGFR mutations [11-15]. Given the rarity of these mutations and the fact they are mostly studied in surgically resected patients, the clinical characteristics and outcomes of advanced NSCLC patients with EGFR exon 20 insertion mutations have not been fully established.

\section{Materials and Methods}

\section{Patients}

Between January 2009 and December 2017, histologically confirmed Samsung Medical Center NSCLC patients with activating EGFR mutations were selected from an institutional database. Among them, patients with an EGFR exon 20 insertion mutation were retrospectively analyzed for clinicopathological characteristics, responses to systemic chemotherapy or targeted agents, PFS, and OS.

\section{EGFR mutation tests}

Mutational analyses of EGFR (exons 18-21) were performed as previously described by directional sequencing, by the peptide nucleic acid clamp method, or by next-generation sequencing [16].

\section{Statistical analysis}

All available data were retrospectively collected using a standardized case report form. OS and PFS were calculated using the Kaplan-Meier method. The Cox proportional hazards regression model was used to evaluate the impact of collected variables on PFS and OS. Two-sided p-values were set at a 0.05 significance level. All analyses were performed using SPSS ver. 23.0 software (IBM Corp., Armonk, NY).

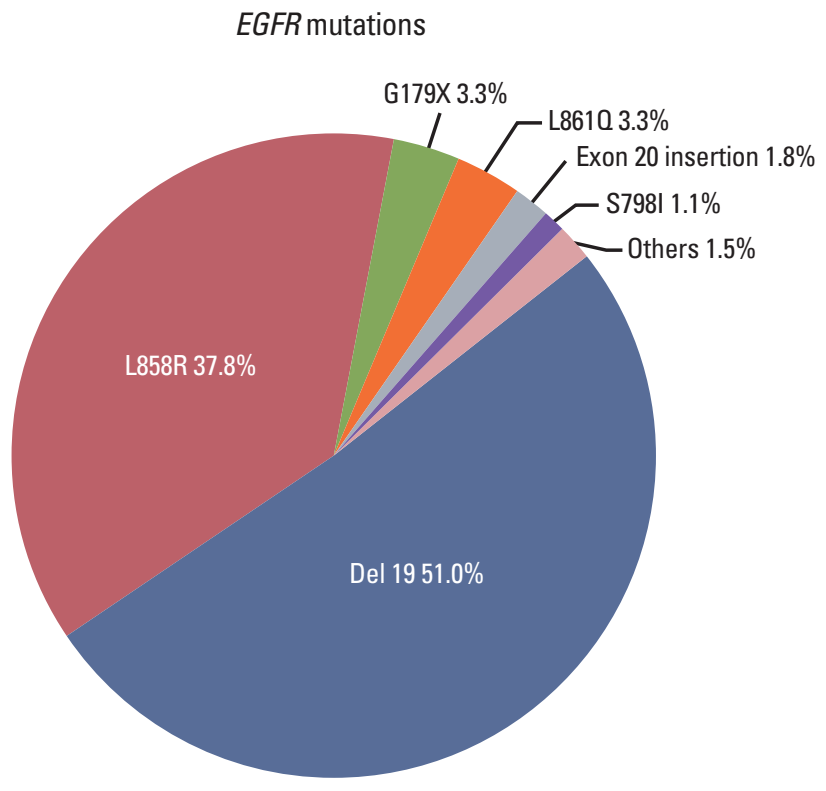

Fig. 1. Distribution of epidermal growth factor receptor (EGFR) mutations in advanced non-small cell lung cancer patients $(\mathrm{n}=1,479)$.

\section{Ethical statement}

Institutional Review Board (IRB) approval was obtained from Samsung Medical Center (SMC, Seoul, Korea, SMC 2018-02-019). The IRB approved waiver of informed consent.

\section{Results}

\section{Prevalence of EGFR mutations}

From January 2009 to December 2017, 3,539 patients showed positive results in the EGFR mutation test. Among them, 1,712 (48.3\%) had an exon 19 deletion, 1,451 (41.0\%) had L858R, $132(3.7 \%)$ had G719X, $92(2.6 \%)$ had L861Q, 56 $(1.6 \%)$ had an exon 20 insertion, and $34(1.0 \%)$ had S768I (S1 Fig.). Among the 56 patients with an exon 20 insertion, eight had an additional mutation: four had an exon 19 deletion, two had L858R, one had G719S, and one had S768I.

Of the 3,539 total patients, 1,479 had advanced NSCLC. These patients included $752(50.8 \%)$ with an exon 19 deletion, $557(37.7 \%)$ with L858R, 49 (3.3\%) with G719X, 49 (3.3\%) with L861Q, 27 (1.8\%) with an exon 20 insertion, and 17 (1.1\%) with S768I (Fig. 1). 
Table 1. Clinical characteristics of total 3,539 patients with NSCLC

\begin{tabular}{lccc} 
& Common $(\mathbf{n}=3,163)$ & Uncommon $(\mathbf{n}=376)$ & p-value \\
Age at diagnosis $(\mathbf{y r})$ & $61(19-92)$ & $62(27-87)$ & NS \\
$\begin{array}{l}\text { Sex } \\
\text { Female }\end{array}$ & $2,008(63.5)$ & $217(57.7)$ & 0.032 \\
$\quad$ Male & $1,155(36.5)$ & $159(42.3)$ & \\
Histology & & & \\
ADC & $3,077(97.3)$ & $335(89.1)$ & $<0.001$ \\
SqCC & $47(1.5)$ & $20(5.3)$ & \\
Others & $39(1.2)$ & $21(5.6)$ & \\
Stage & & & \\
$\quad$ I-IIIA & $1,866(59.0)$ & $194(51.6)$ & 0.007 \\
IIIB-IV & $1,297(41.0)$ & $182(48.4)$ & \\
\hline
\end{tabular}

Values are presented as median (range) or number (\%). NSCLC, non-small cell lung cancer; NS, non-significant; ADC, adenocarcinoma; SqCC, squamous cell carcinoma.

Table 2. Baseline characteristics of patients with an exon 20 insertion mutation

\begin{tabular}{|c|c|c|c|}
\hline & $\begin{array}{l}\text { Early-stage } \\
\quad(n=29)\end{array}$ & $\begin{array}{l}\text { Refractory NSCLC } \\
(\mathrm{n}=27)\end{array}$ & $\begin{array}{c}\text { Total } \\
(\mathrm{n}=56)\end{array}$ \\
\hline Age at diagnosis (yr) & $60(36-78)$ & $60(43-75)$ & $60(36-78)$ \\
\hline \multicolumn{4}{|l|}{ Sex } \\
\hline Female & $14(48.2)$ & $11(40.7)$ & $25(44.6)$ \\
\hline Male & $15(51.8)$ & $16(59.3)$ & $33(55.4)$ \\
\hline \multicolumn{4}{|l|}{ Histology } \\
\hline $\mathrm{ADC}$ & $29(100)$ & $26(96.3)$ & $55(98.2)$ \\
\hline $\mathrm{SqCC}$ & 0 & $1(3.7)$ & $1(1.8)$ \\
\hline \multicolumn{4}{|l|}{ ECOG } \\
\hline 0 & $8(27.6)$ & $1(3.8)$ & $9(16.1)$ \\
\hline 1 & $21(72.4)$ & $19(70.3)$ & 40 (71.4) \\
\hline 2 & 0 & $7(25.9)$ & $7(12.5)$ \\
\hline \multicolumn{4}{|l|}{ Smoking history } \\
\hline Never & $19(65.5)$ & $21(77.8)$ & 40 (71.4) \\
\hline Current & $6(20.7)$ & $3(11.1)$ & $9(16)$ \\
\hline Ex & $4(13.8)$ & $3(11.1)$ & $7(12.6)$ \\
\hline \multicolumn{4}{|l|}{ Metastasis } \\
\hline CNS & - & 11 & - \\
\hline Bone & - & 9 & - \\
\hline Liver & - & 5 & - \\
\hline Lung & - & 9 & - \\
\hline \multicolumn{4}{|l|}{ Exon 20 mutation } \\
\hline Insertion only & $25(8-6.2)$ & $23(85.2)$ & - \\
\hline \multicolumn{4}{|l|}{ Double mutation } \\
\hline Insertion+S768I & - & $1(3.7)$ & - \\
\hline Insertion+G719S & - & $1(3.7)$ & - \\
\hline Insertion+Deletion 19 & $4(13.8)$ & - & - \\
\hline Insertion+L858R & - & $2(7.4)$ & - \\
\hline
\end{tabular}

Values are presented as median (range) or number (\%). NSCLC, non-small cell lung cancer; ADC, adenocarcinoma; SqCC, squamous cell carcinoma; ECOG, Eastern Cooperative Oncology Group; CNS, central nervous system. 


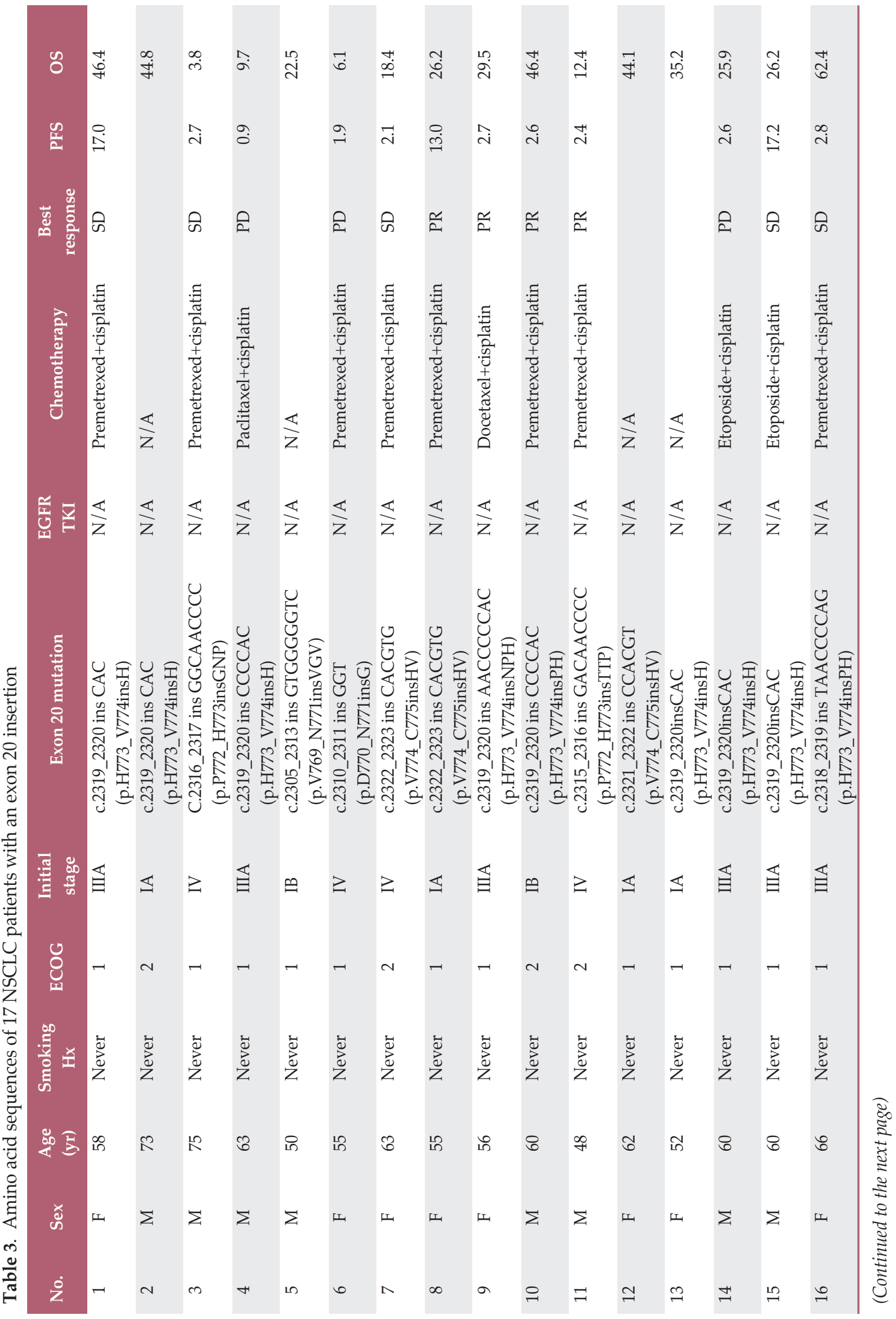




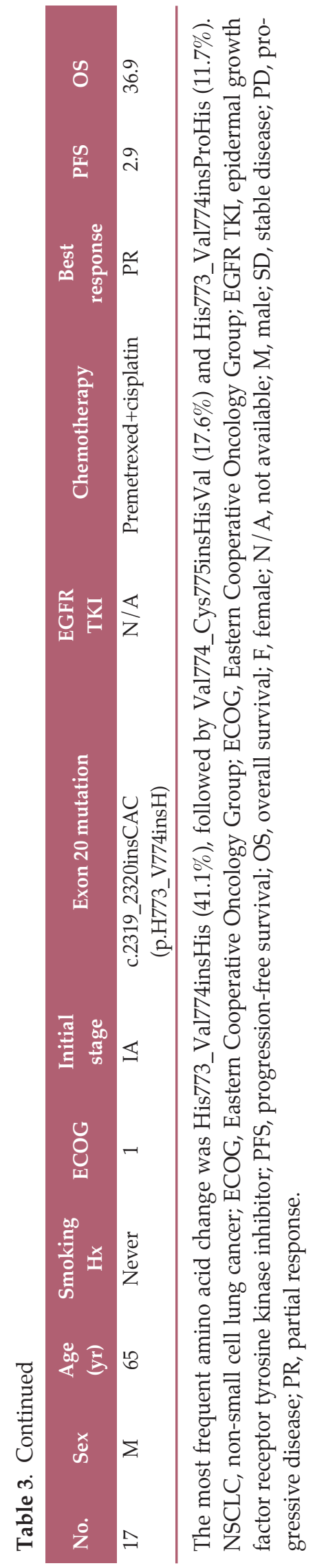

\section{Characteristics of patients with exon 20 insertion muta- tion}

Among total 3,539 patients, 3,163 patients were identified that having common EGFR mutations, meanwhile 376 patients were uncommon EGFR mutations. Demographic characteristics of total 3,539 patients were summarized in Table 1. Women, adenocarcinoma, and early staged NSCLC patients were more common in NSCLC patients with common EGFR mutations.

Baseline characteristics of 27 advanced NSCLC patients harboring an exon 20 insertion mutation are summarized in Table 2. The median follow-up duration was 12.1 months (range, 0.9 to 62.4 months). The median age at diagnosis was 60 years (range, 43 to 75 years), and $41 \%$ of patients were female. A majority of patients $(78 \%)$ were never-smokers, and most $(96 \%)$ had adenocarcinoma. The most common metastatic sites were the central nervous system $(40.7 \%)$, lung $(33.3 \%)$, bone $(33.3 \%)$, and liver $(18.5 \%)$. Of note, 23 patients had only an exon 20 insertion mutation, while four patients had an additional activating mutation: two had L858R, one had S768I, and one had G719S (Table 2).

\section{Types of exon 20 insertion mutations}

Among 27 patients with exon 20 insertions, only 17 had available data for amino acid position changes. All exon 20 insertions were clustered between Val769 and Val775. His773_Val774insHis was the most common insertion mutation $(\mathrm{n}=7,41.2 \%)$, followed by Val774_Cys775insHisVal $(\mathrm{n}=3$, $17.7 \%)$ and His773_Val774insProHis $(n=2,11.7 \%)$. Each of the following mutations was found one time: His773_Val774insAsnProHis, Pro772_His773insThrThrPro, Pro772_His773insGlyAsnPro, Val769_Asn771insValGlyVal, and Asp770_Asn771insGly (Table 3).

\section{Treatment responses and clinical outcomes}

Of the 27 patients with exon 20 insertions, 22 received platinum-based systemic chemotherapy. The overall response rate (ORR) was $50.0 \%$, and the disease control rate was $77.2 \%$. The median PFS was 4.2 months (95\% confidence interval [CI], 1.7 to 6.6), and the median OS was 29.4 months (95\% CI, 9.3 to 49.6) (Fig. 2). In contrast, all patients with a double mutation were still alive at the time of last follow-up (November 15, 2017; OS range, 2.2 to 15.0 months). A Cox proportional regression analysis revealed that central nervous system metastasis was associated with poor OS ( $p=0.043$, data not shown).

Six patients were treated with an EGFR TKI. Three patients received a reversible EGFR TKI (erlotinib), and the other three received an irreversible EGFR TKI (two received afa- 
A
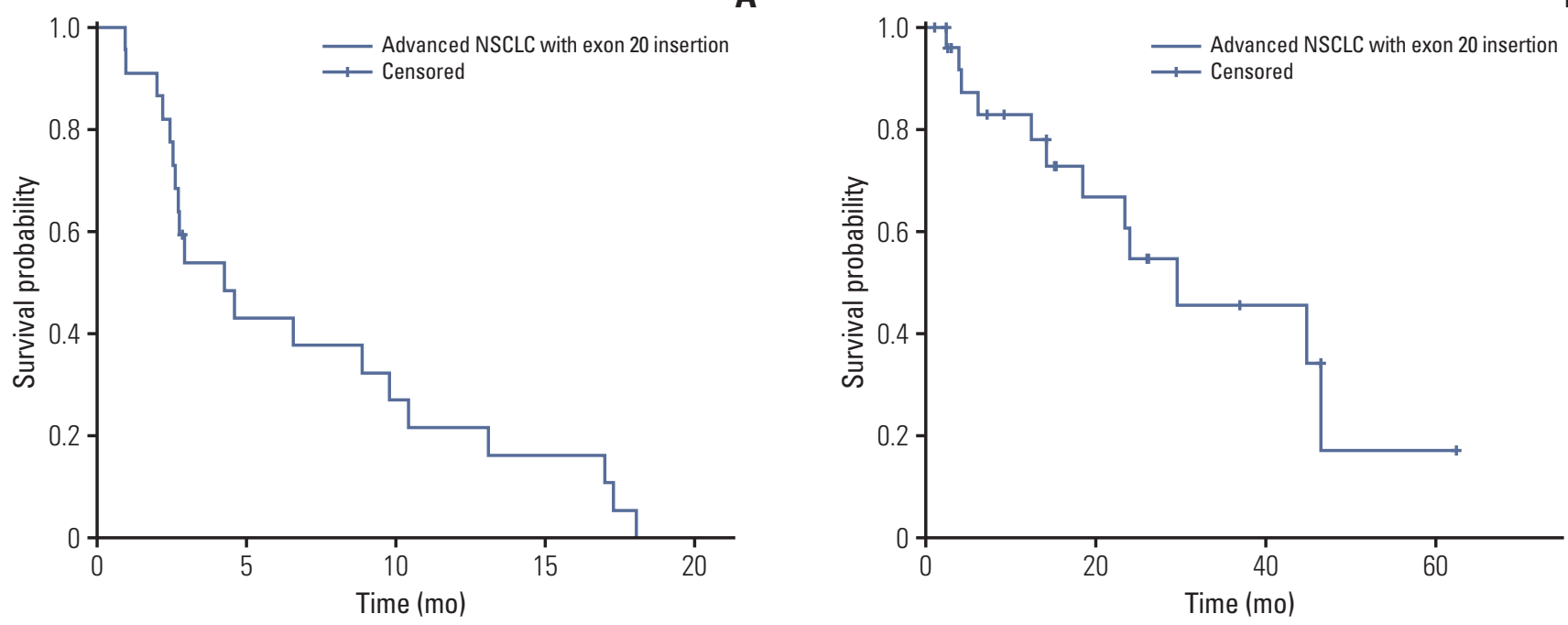

Fig. 2. Kaplan-Meier survival curves. (A) Progression-free survival of patients with an exon 20 insertion receiving systemic chemotherapy. (B) Overall survival of patients with an exon 20 insertion. NSCLC, non-small cell lung cancer.

Table 4. Clinical information and treatment outcomes of six patients who received EGFR TKIs

\begin{tabular}{|c|c|c|c|c|c|c|c|c|}
\hline Sex & $\begin{array}{l}\text { Age } \\
(\mathrm{yr})\end{array}$ & Exon 20 type & ECOG & Smoking history & $\begin{array}{l}\text { Initial } \\
\text { stage }\end{array}$ & TKI type & $\begin{array}{c}\text { EGFR TKI } \\
\text { response }\end{array}$ & PFS \\
\hline $\mathrm{F}$ & 44 & Insertion & 1 & Never-smoker & IV & Erlotinib & PD & 0.7 \\
\hline M & 65 & Insertion & 2 & Never-smoker & IV & Afatinib & PD & 0.9 \\
\hline M & 60 & Insertion & 1 & Current smoker 30PY & IV & Erlotinib & PD & 2.6 \\
\hline M & 48 & Insertion & 0 & Ex-smoker 20PY & IV & Erlotinib & SD & 11.4 \\
\hline M & 62 & Insertion+L858R & 1 & Ex-smoker 10PY & IIB & Afatinib & PR & 1.9 \\
\hline $\mathrm{F}$ & 43 & Insertion+G719S & 1 & Never-smoker & IV & Osimertinib & PR & 2.8 \\
\hline
\end{tabular}

EGFR TKI, epidermal growth factor receptor tyrosine kinase inhibitor; ECOG, Eastern Cooperative Oncology Group; PFS, progression-free survival; F, female; M, male; PD, progressive disease; SD, stable disease; PR, partial response.

Table 5. Published studies evaluating clinical response to EGFR TKIs in NSCLC patients with exon 20 insertion

\begin{tabular}{lccccc} 
Study & $\begin{array}{c}\text { Type of EGFR Exon } \\
\text { 20 mutation }\end{array}$ & $\begin{array}{c}\text { Patients treated } \\
\text { with EGFR TKIs }\end{array}$ & $\begin{array}{c}\text { ORR to } \\
\text { TKI (\%) }\end{array}$ & $\begin{array}{c}\text { PFS to } \\
\text { TKI }\end{array}$ \\
\hline Tu et al. [18] & Insertion 20 & 12 & 0 & $3.0(1.3-4.7)$ & $12.5(0-25.5)$ \\
Lund-Iversen et al. [13] & Insertion 20 & 3 & 0 & - & - \\
Arcila et al. [15] & Insertion 20 & 5 & 40 & 2.5 & - \\
\hline Naidoo et al. [12] & Insertion 20 & 11 & 27 & - & - \\
Yasuda et al. [17] & Insertion 20 & 19 & 11 & $2.9(2.3-3.6)$ & 9.7 \\
Kuiper et al. [19] & Insertion 20 & 16 & 0 & $2.6(0.7-11.4)$ & $29.4(9.3-49.6)$ \\
\hline Current study & Insertion 20 & 4 & 25 & - \\
\hline
\end{tabular}

EGFR TKI, epidermal growth factor receptor tyrosine kinase inhibitor; NSCLC, non-small cell lung cancer; ORR, objective response rate; PFS, progression free survival; OS, overall survival. 
tinib, and one received osimertinib). Among the four patients with only an exon 20 insertion, three had progressive disease and one had stable disease. In contrast, the two doublemutation patients achieved a partial response to treatment (Table 4).

\section{Discussion}

We found that exon 20 insertion mutations represented $1.6 \%$ of all EGFR mutations, regardless of the cancer stage. Exon 20 insertions represented 1.8\% of the EGFR mutations found in cases of advanced NSCLC, consistent with previous reports $[6,11,12,14]$. These patients shared similar characteristics with patients harboring other common EGFR mutations in that the majority had adenocarcinoma (96\%) and were never-smokers (78\%).

Amino acid sequencing data from the exon 20 insertion mutations indicated that the majority $(88.2 \%)$ showed changes after His773. The most frequent amino acid change was His773_Val774insHis (41.1\%), followed by Val774_Cys775insHisVal (17.6\%) and His773_Val774insProHis (11.7\%). All amino acid changes occurred between Val769 and Val775, in a region located just after the C-helix of the EGFR tyrosine kinase domain. These findings are consistent with the results of Yasuda et al. [17]. We observed three novel amino acid sequence variants: Pro772_His773insGly AsnPro, Val769_Asn771insValGlyVal, and Pro772_His773insThrThrPro. This suggests that exon 20 insertion mutations are highly variable and heterogeneous. Although the clinical significance of these novel sequences has not been established, efforts to find new amino acid sequences in exon 20 mutations are warranted.

It has been suggested that exon 20 insertions and other types of EGFR mutations are mutually exclusive [11-14,16]. Among the 56 patients with exon 20 insertions in our study, eight had an additional EGFR mutation to the exon 20 insertion, such as L858R, an exon 19 deletion, S768I, or G719S. Patients with a double mutation comprising an exon 20 insertion and L858R or G719S initially achieved a partial response to EGFR TKIs. However, the PFS was short (1.9-2.9 months), suggesting that exon 20 insertion might be dominant over the other more common mutation. Further validation of these results is needed. As expected, patients with an exon 20 insertion only who received EGFR TKIs had a low response rate and short PFS ( 2.6 months; range, 0.7 to 11.4), consistent with previous reports $[12,14,15,20]$.

One patient showed a long duration of stable disease following treatment with an EGFR TKI. Some exon 20 insertions (such as A763_Y764insFQEA) are relatively sensitive to
EGFR TKIs, and this patient may have had such a variant [12,21].

In general, exon 20 insertion mutation in NSCLC is associated with lack of sensitivity to first-generation EGFR TKIs, such as erlotinib or gefitinib [12-14,18,19], and so does our study (Table 5). The exact mechanism underlying this lack of sensitivity has not been fully established. It is possible that exon 20 insertions occurring after the C-helix might induce conformational changes that affect the binding affinity to EGFR inhibitors, promoting resistance to EGFR TKIs [17]. Kosaka et al. showed that replacing Asp770 with Gly770 restored sensitivity to EGFR TKIs by allowing Arg776 access. This facilitated a C-helix conformational change and substrate binding in $\mathrm{Ba} / \mathrm{F} 3$ cells transduced with an EGFR exon 20 insertion mutation [22].

In one pre-clinical study, patient derived xenografts cells harboring an EGFR exon 20 insertion showed a partial response to second-generation (afatinib) and third-generation (osimertinib and rociletinib) TKIs [23]. Another pre-clinical study showed that a novel, mutant-selective inhibitor of EGFR (nazartinib) showed promising results in vitro in cancer-derived cell lines expressing exon 20 insertions. Nazartinib was effective for the duration of the therapeutic window, at only half the maximal inhibitory concentration $\left(\mathrm{IC}_{50}\right)$ [24]. But in clinical trials to date, promising results have not been observed with currently available agents designed to target EGFR [25,26]. Therefore, further studies are needed to enhance our understanding of the EGFR structure and to clarify the mechanisms by which exon 20 insertions affect patient responses to EGFR TKIs. As part of these efforts, one phase II study of poziotinib in patients with advanced NSCLC and EGFR exon 20 mutations had been conducted. In this study, seven of 11 patients achieved a partial response to poziotinib, suggesting its promising efficacy [27].

In this study, the advanced NSCLC patients with exon 20 insertion had median OS of 29.4 months (95\% CI, 9.3 to 49.6), which is consistent with median OS of advanced NSCLC with common EGFR mutations [8,9]. The ORR and PFS to platinum-based chemotherapy were $50 \%$ and 4.2 months, respectively. Considering the poor outcomes with EGFR TKIs, platinum-based systemic chemotherapy is considered standard treatment for advanced NSCLC with an exon 20 insertion mutation $[12,20]$.

The present study has certain limitations. Given the small number of patients and retrospective nature of the analysis, patients analyzed in this cohort might not be representative of all types of advanced NSCLC with EGFR exon 20 insertion mutations. Furthermore, the various techniques used in this study to detect EGFR mutations have inherently different levels of specificity and sensitivity. Nevertheless, we analyzed one of the largest cohorts of its kind, with more than 3,000 patients with activating EGFR mutations. 
In conclusion, exon 20 insertion mutations are rare in Korea, and are occasionally accompanied by common EGFR mutations. Although the response to systemic chemotherapy in these patients is comparable to that in patients with more common EGFR mutations, the response rate to first- or second-generation EGFR TKIs is quite low. For this reason, the development of a more efficient chemotherapeutic agent is urgently needed.

\section{Electronic Supplementary Material}

Supplementary materials are available at Cancer Research and Treatment website (https://www.e-crt.org).

\section{Conflicts of Interest}

Conflict of interest relevant to this article was not reported.

\section{References}

1. Torre LA, Bray F, Siegel RL, Ferlay J, Lortet-Tieulent J, Jemal A. Global cancer statistics, 2012. CA Cancer J Clin. 2015;65:87108.

2. Jung KW, Won YJ, Oh CM, Kong HJ, Lee DH, Lee KH, et al. Cancer statistics in Korea: incidence, mortality, survival, and prevalence in 2014. Cancer Res Treat. 2017;49:292-305.

3. Oser MG, Niederst MJ, Sequist LV, Engelman JA. Transformation from non-small-cell lung cancer to small-cell lung cancer: molecular drivers and cells of origin. Lancet Oncol. 2015;16: e165-72.

4. Lynch TJ, Bell DW, Sordella R, Gurubhagavatula S, Okimoto RA, Brannigan BW, et al. Activating mutations in the epidermal growth factor receptor underlying responsiveness of nonsmall-cell lung cancer to gefitinib. N Engl J Med. 2004;350: 2129-39.

5. Fukui T, Otani S, Hataishi R, Jiang SX, Nishii Y, Igawa S, et al. Successful rechallenge with erlotinib in a patient with EGFRmutant lung adenocarcinoma who developed gefitinib-related interstitial lung disease. Cancer Chemother Pharmacol. 2010; 65:803-6.

6. Rosell R, Moran T, Queralt C, Porta R, Cardenal F, Camps C, et al. Screening for epidermal growth factor receptor mutations in lung cancer. N Engl J Med. 2009;361:958-67.

7. Zhou C, Wu YL, Chen G, Feng J, Liu XQ, Wang C, et al. Erlotinib versus chemotherapy as first-line treatment for patients with advanced EGFR mutation-positive non-smallcell lung cancer (OPTIMAL, CTONG-0802): a multicentre, open-label, randomised, phase 3 study. Lancet Oncol. 2011; 12:735-42.

8. Rosell R, Carcereny E, Gervais R, Vergnenegre A, Massuti B, Felip E, et al. Erlotinib versus standard chemotherapy as firstline treatment for European patients with advanced EGFR mutation-positive non-small-cell lung cancer (EURTAC): a multicentre, open-label, randomised phase 3 trial. Lancet Oncol. 2012;13:239-46.

9. Mok TS, Wu YL, Thongprasert S, Yang CH, Chu DT, Saijo N, et al. Gefitinib or carboplatin-paclitaxel in pulmonary adenocarcinoma. N Engl J Med. 2009;361:947-57.

10. Pao W, Chmielecki J. Rational, biologically based treatment of EGFR-mutant non-small-cell lung cancer. Nat Rev Cancer. 2010;10:760-74.
11. Wu JY, Wu SG, Yang CH, Gow CH, Chang YL, Yu CJ, et al. Lung cancer with epidermal growth factor receptor exon 20 mutations is associated with poor gefitinib treatment response. Clin Cancer Res. 2008;14:4877-82.

12. Naidoo J, Sima CS, Rodriguez K, Busby N, Nafa K, Ladanyi $\mathrm{M}$, et al. Epidermal growth factor receptor exon 20 insertions in advanced lung adenocarcinomas: clinical outcomes and response to erlotinib. Cancer. 2015;121:3212-20.

13. Lund-Iversen M, Kleinberg L, Fjellbirkeland L, Helland A, Brustugun OT. Clinicopathological characteristics of 11 NSCLC patients with EGFR-exon 20 mutations. J Thorac Oncol. 2012;7:1471-3.

14. Beau-Faller M, Prim N, Ruppert AM, Nanni-Metellus I, Lacave R, Lacroix L, et al. Rare EGFR exon 18 and exon 20 mutations in non-small-cell lung cancer on 10117 patients: a multicentre observational study by the French ERMETIC-IFCT network. Ann Oncol. 2014;25:126-31.

15. Arcila ME, Nafa K, Chaft JE, Rekhtman N, Lau C, Reva BA, et al. EGFR exon 20 insertion mutations in lung adenocarcinomas: prevalence, molecular heterogeneity, and clinicopathologic characteristics. Mol Cancer Ther. 2013;12:220-9.

16. Lee JY, Lim SH, Kim M, Kim S, Jung HA, Chang WJ, et al. Is there any predictor for clinical outcome in EGFR mutant NSCLC patients treated with EGFR TKIs? Cancer Chemother Pharmacol. 2014;73:1063-70.

17. Yasuda H, Park E, Yun CH, Sng NJ, Lucena-Araujo AR, Yeo WL, et al. Structural, biochemical, and clinical characterization of epidermal growth factor receptor (EGFR) exon 20 insertion mutations in lung cancer. Sci Transl Med. 2013;5:216ra177.

18. Tu HY, Ke EE, Yang JJ, Sun YL, Yan HH, Zheng MY, et al. A comprehensive review of uncommon EGFR mutations in patients with non-small cell lung cancer. Lung Cancer. 2017;114:96-102.

19. Kuiper JL, Hashemi SM, Thunnissen E, Snijders PJ, Grunberg $\mathrm{K}$, Bloemena E, et al. Non-classic EGFR mutations in a cohort of Dutch EGFR-mutated NSCLC patients and outcomes following EGFR-TKI treatment. Br J Cancer. 2016;115:1504-12.

20. Oxnard GR, Lo PC, Nishino M, Dahlberg SE, Lindeman NI, Butaney $\mathrm{M}$, et al. Natural history and molecular characteristics of lung cancers harboring EGFR exon 20 insertions. J Thorac Oncol. 2013;8:179-84. 
21. Lin YT, Liu YN, Wu SG, Yang JC, Shih JY. Epidermal growth factor receptor tyrosine kinase inhibitor-sensitive exon 19 insertion and exon 20 insertion in patients with advanced nonsmall-cell lung cancer. Clin Lung Cancer. 2017;18:324-32.e1.

22. Kosaka T, Tanizaki J, Paranal RM, Endoh H, Lydon C, Capelletti $\mathrm{M}$, et al. Response heterogeneity of EGFR and HER2 exon 20 insertions to covalent EGFR and HER2 inhibitors. Cancer Res. 2017;77:2712-21.

23. Yang M, Xu X, Cai J, Ning J, Wery JP, Li QX. NSCLC harboring EGFR exon-20 insertions after the regulatory C-helix of kinase domain responds poorly to known EGFR inhibitors. Int J Cancer. 2016;139:171-6.

24. Masuzawa K, Yasuda H, Hamamoto J, Nukaga S, Hirano T, Kawada I, et al. Characterization of the efficacies of osimertinib and nazartinib against cells expressing clinically relevant epidermal growth factor receptor mutations. Oncotarget. 2017;8:105479-91.

25. Shen YC, Tseng GC, Tu CY, Chen WC, Liao WC, Chen WC, et al. Comparing the effects of afatinib with gefitinib or Erlotinib in patients with advanced-stage lung adenocarcinoma harboring non-classical epidermal growth factor receptor mutations. Lung Cancer. 2017;110:56-62.

26. Janne PA, Boss DS, Camidge DR, Britten CD, Engelman JA, Garon EB, et al. Phase I dose-escalation study of the pan-HER inhibitor, PF299804, in patients with advanced malignant solid tumors. Clin Cancer Res. 2011;17:1131-9.

27. Robichaux JP, Elamin YY, Tan Z, Carter BW, Zhang S, Liu S, et al. Mechanisms and clinical activity of an EGFR and HER2 exon 20-selective kinase inhibitor in non-small cell lung cancer. Nat Med. 2018;24:638-46. 